\title{
Erratum to: Estimating belowground biomass and root/shoot ratio of Phillyrea latifolia $L$. in the Mediterranean forest landscapes
}

Pasquale A. Marziliano ${ }^{1} \cdot$ Raffaele Lafortezza $^{2} \cdot$ Umberto Medicamento $^{2} \cdot$
Leonardo Lorusso $^{3} \cdot$ Vincenzo Giannico $^{2} \cdot$ Giuseppe Colangelo $^{2} \cdot$ Giovanni Sanesi $^{2}$

Published online: 24 April 2017

(C) INRA and Springer-Verlag France 2017

Erratum to: Annals of Forest Science

DOI: 10.1007/s13595-015-0486-5

Unfortunately, the name of one of the authors was incorrectly spelled. The correct name is Vincenzo Giannico.

The online version of the original article can be found at http://dx.doi.org/ 10.1007/s13595-015-0486-5

Giovanni Sanesi

giovanni.sanesi@uniba.it

1 Department of Agraria, Mediterranean University of Reggio Calabria, Reggio Calabria, Italy

2 Department of Agricultural and Environmental Sciences, University of Bari A. Moro, Via Amendola 165/A, 70126 Bari, Italy

3 Municipality of Monopoli, BA, Italy 